\title{
MASSA DE FORRAGEM E CARACTERÍSTICAS MORFOLÓGICAS DE GRAMÍNEAS DO GÊNERO BRACHIARIA NA REGIÃO DO ARENITO CAIUÁ/PR ${ }^{1}$
}

\author{
K. F. GobBi²*, S. M. B. Lugão², V. BetT² J. J. S. AbrahÃo², A. A. K. TACAiAma²
}

${ }^{1}$ Recebido em 02/04/2018. Aprovado em 26/06/2018.

${ }^{2}$ Instituto Agronômico do Paraná, Paranavaí, PR, Brasil.

*Autor correspondente: kfgobbi@iapar.br

\begin{abstract}
RESUMO: Na região Noroeste do Paraná, assim como em boa parte do Brasil, as espécies forrageiras mais utilizadas são as gramíneas do gênero Brachiaria, com destaque para a Brachiaria brizantha cv. Marandu. Contudo, existem novas cultivares que precisam ser avaliadas. O objetivo deste estudo foi avaliar a massa de forragem, características morfológicas e alturas de manejo (95\% interceptação luminosa do dossel) de cinco cultivares de Brachiaria brizantha (Marandu, Xaraés, Piatã, Paiaguás e MG-4) e a Brachiaria híbrida Convert HD 364. Utilizou-se delineamento inteiramente casualizado, com seis tratamentos e quatro repetições. Foram avaliados a altura e interceptação luminosa do dossel, massa de forragem e composição morfológica das plantas. As cultivares Xaraés, Paiaguás e MG-4 destacaram-se pela maior massa de forragem total e de folhas, particularmente na época seca, e são boas alternativas para a cultivar Marandu. A altura do dossel forrageiro de entrada preconizada para as cultivares Marandu e Piatã está em torno de $25 \mathrm{~cm}$, para Xaraés e MG- $30 \mathrm{~cm}$, Paiaguás $34 \mathrm{~cm}$, e Convert $23 \mathrm{~cm}$.
\end{abstract}

Palavras-chave: Altura do dossel, IAF crítico, interceptação luminosa.

\section{FORAGE MASS AND MORPHOLOGICAL CHARACTERISTICS OF GRASSES FROM GENUS BRACHIARIA IN CAIUÁ SANDSTONE REGION, PARANÁ}

\begin{abstract}
Grasses from genus Brachiaria are widely used for grazing systems in the Northwest of Paraná, as well as throughout Brazil. Marandu palissadegrass is the most used cultivar, but there are some options that need to be evaluated. The objective of this study was to evaluate forage mass, morphological characteristics and sward heigth (at 95\% canopy light interception) of five Brachiaria brizantha cultivars (Marandu, Xaraés, Piatã, Paiaguás and MG-4) and Brachiaria hybrid Convert HD 364. A completely randomized design was used, with six treatments and four replicates. Sward height, light interception, forage mass and morphological composition were evaluated. The cultivars Xaraés, Paiaguás and MG-4 stood out for the greater total and leaves forage mass, particularly in the dry season. These materials are good alternatives for the Marandu cultivar. The pre-grazing sward height recommended for cultivars Marandu and Piatã was $25 \mathrm{~cm}$, Xaraés and MG-4 is $30 \mathrm{~cm}$, Paiaguás $34 \mathrm{~cm}$, and Convert $23 \mathrm{~cm}$.
\end{abstract}

Key words: Sward height, leaf area index, light interception. 


\section{INTRODUÇÃO}

O aumento da produtividadee rentabilidade das áreas de pastagem depende de vários fatores, entre eles o uso de espécies forrageiras produtivas e adaptadas às condições edafoclimáticas do local onde são cultivadas, bem como o investimento em adubação e manejo adequados.

A bovinocultura de corte está distribuída em todo o estado do Paraná, porém com maior concentração nas regiões Norte e Noroeste, que respondem por $57,64 \%$ do rebanho estadual (BorGES E MEZZADRI, 2008). Na região Noroeste do Paraná, assim como ocorre em boa parte do Brasil, as espécies mais utilizadas na bovinocultura de corte são as gramíneas do gênero Brachiaria, podendo-se destacar o capimmarandu \{Brachiaria brizantha (Hochst. Ex A. Rich.) R. D. Webster [syn. Urochloa brizantha (A. Rich.) Stapf] cv. Marandu\}, e alguns do gênero Panicum (Tanzânia, Mombaça, etc.).

O capim-marandu, lançado pela Embrapa em 1984, é uma das forrageiras mais plantadas no Brasil nos últimos 15 anos, ocupando cerca de 70 milhões de hectares. Destaca-se pela boa adaptação a solos de média a alta fertilidade, sendo resistente à cigarrinha-das-pastagens, com boa produção e qualidade de forragem, elevada resposta à adubação, boa produção de sementes e boa cobertura do solo. É de fácil estabelecimento e apresenta grande capacidade de competição com invasoras (CosTA et al., 2009).

Contudo, a grande área ocupada pelo capim-marandu pode contribuir para o aumento da pressão de seleção para pragas e doenças (MACEDO, 2006). De acordo com JANK et al. (2011), apesar dos inúmeros esforços das instituições de pesquisa para lançar novas cultivares, o número efetivamente utilizado pelos produtores ainda é pequeno, e o uso de poucas cultivares em grandes áreas gera a vulnerabilidade dos sistemas de produção. Algumas cultivares de Brachiaria brizantha, são muito utilizadas na pecuária de corte do Noroeste Paranaense, sendo necessárias, contudo, mais avaliações do comportamento de cada cultivar para obtenção de informações quanto ao manejo adequado de cada uma na região.

Os solos predominantes na região do Arenito Caiuá Paranaense apresentam grandes restrições para as atividades agropecuárias. São solos arenosos, com baixa capacidade de retenção de água, alta friabilidade e alta susceptibilidade à erosão hídrica ou eólica. Além disso, apresentam baixa fertilidade natural com baixos teores de fósforo, potássio, cálcio, magnésio e matéria orgânica, bem como uma capacidade de troca de cátions altamente dependente da matéria orgânica (Muzillı et al., 1990). Assim, faz-se necessária a avaliação de gramíneas alternativas do gênero Brachiaria, proporcionando maior diversificação na exploração pecuária (EuCLIDES et al., 2009). Para tanto, foi estabelecido ensaio experimental para avaliação da massa de forragem, características morfológicas e alturas de manejo (aos 95\% interceptação luminosa do dossel) de cultivares de BRACHIARIA BRIZANTHA (Marandu, Xaraés, Piatã, MG4, Paiaguás) e Brachiaria híbrida Convert HD 364, para se determinar as melhores alternativas para o capim-marandu na região.

\section{MATERIAL E MÉTODOS}

O ensaio experimental foi realizado na Estação Experimental do IAPAR em Paranavaí, região Noroeste do Paraná. O tipo climático predominante nesta região é o Cfa - clima subtropical (mesotérmico), pela classificação de KöPPEN (IAPAR, 2000), com verões quentes, geadas pouco frequentes e tendência de concentração das chuvas nos meses de verão (período de outubro a abril). A temperatura média anual é de aproximadamente 22 graus e a precipitação média anual fica entre 1400 e 1600 $\mathrm{mm}$. Os dados de precipitação e temperatura foram coletados em estação meteorológica próxima da área experimental (Figura 1).

De acordo com FIDALSKI et al. (2008) o solo da região é classificado como Latossolo Vermelho distrófico textura arenosa média, com frações de $89,2 \%$ de areia, $1,0 \%$ de silte e $9,8 \%$ de argila na camada de 0 a $15 \mathrm{~cm}$.

Antes da implantação das parcelas, foi realizada análise química o solo, que foi corrigido utilizando-se calcário dolomítico para elevar ao nível de $70 \%$ a saturação de bases. Também foi realizada correção para elevar o nível de fósforo a 18 ppm e de potássio para $5 \%$ da capacidade de troca de cátions (CTC). A área experimental foi preparada de forma convencional, com aração e gradagem 


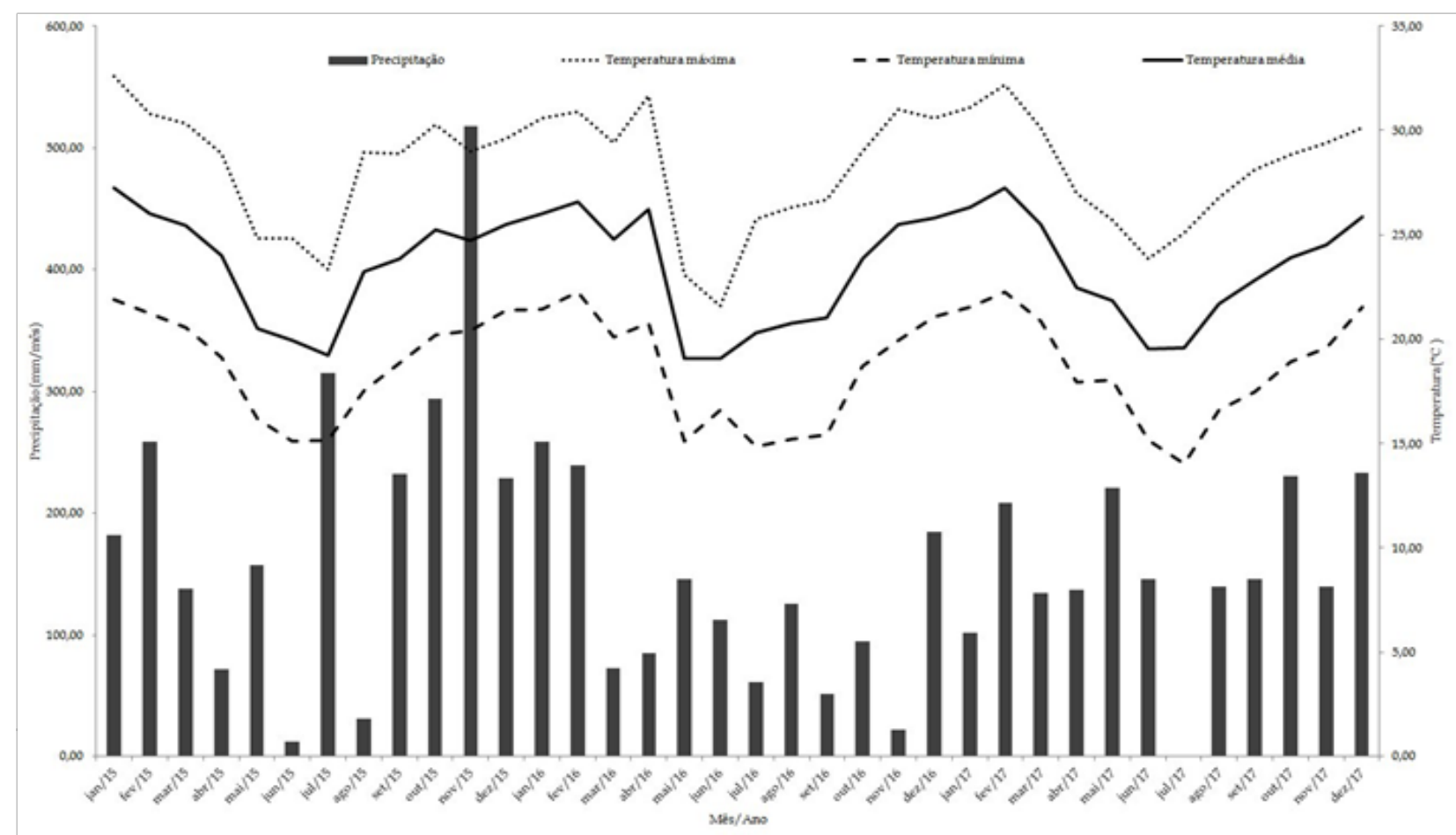

Figura 1. Precipitação pluviométrica e temperaturas máximas, médias e mínimas de janeiro de 2015 a dezembro de 2017.

de nivelamento, cerca de trinta dias antes da semeadura.

A adubação de manutenção foi realizada após cada corte de avaliação, apenas durante o período chuvoso, aplicando-se o equivalente a $40 \mathrm{~kg}$ de nitrogênio e $40 \mathrm{~kg}$ de $\mathrm{K}_{2} \mathrm{O}$ por hectare.

Utilizou-se o delineamento inteiramente casualizado, avaliando-se seis gramíneas do gênero Brachiaria (Brachiaria brizantha cv. Marandu, cv. Xaraés, cv. Piatã, cv. MG4, cv. Paiaguás e Brachiaria híbrida Convert HD 364), com quatro repetições. O estabelecimento foi feito por sementes em parcelas de $25 \mathrm{~m}^{2}(5 \mathrm{x}$ $5 \mathrm{~m})$, totalizando 16 unidades experimentais, com corredores de $2 \mathrm{~m}$ de largura entre as parcelas.

As parcelas experimentais foram estabelecidas em novembro de 2012 (exceto a cv. Paiguás, estabelecida em novembro de 2013). No dia 16 de dezembro de 2014 foi realizado corte de uniformização a $15 \mathrm{~cm}$ de altura e logo em seguida procedeu-se a adubação de manutenção. As avaliações foram realizadas de janeiro de 2015 até dezembro de 2017.

Os períodos de avaliação das plantas foram divididos em ciclos de crescimento, e cada ciclo concluído com o corte das mesmas. O momento do corte foi definido pela interceptação luminosa do dossel. Quando a interceptação de luz pelo dossel forrageiro de cada parcela (4 repetições/forrageira avaliada) atingiu o valor médio de $95 \%$ da luz solar incidente (5 leituras / parcela), foi feito o corte e a coleta de amostras. De acordo com PARsons et al. (1988), quando 95\% da luz incidente são interceptados pelo dossel (IAF crítico), a taxa média de acúmulo de forragem pode atingir seu valor máximo, com o melhor balanço entre os processos de crescimento e senescência.

As parcelas foram monitoradas quanto à interceptação de luz e índice de área foliar (IAF), em intervalos regulares, utilizando-se um analisador de dossel modelo LAI 2000 (LiCOR, Lincoln, Nebraska, EUA). O aparelho calcula de maneira não destrutiva o IAF e outros atributos de estrutura da cobertura vegetal. As medições de radiação são efetuadas por um sensor óptico tipo "olho de peixe", com medidas tomadas acima do dossel e sob o dossel (nível do solo). Foram avaliados pontos representativos da estrutura de cada parcela, na proporção de uma leitura acima do dossel para cinco leituras ao nível do solo.

A altura média do dossel foi determinada utilizando-se régua graduada, fazendo-se 
a medição em cinco pontos diferentes da parcela. Para coleta de material das parcelas foi utilizado quadro de amostragem de 0,24 $\mathrm{m}^{2}(60 \times 40 \mathrm{~cm})$. Coletou-se uma amostra por parcela, cortando-se as plantas a $15 \mathrm{~cm}$ acima do nível do solo. Após as coletas as parcelas foram submetidas a corte de uniformização e na sequência realizou-se a adubação de manutenção.

Todo o material proveniente do quadro de amostragem foi pesado para posterior retirada de sub-amostras. Cada sub-amostra foi separada nos componentes lâmina foliar, colmo e material morto, que posteriormente foram secos separadamente em estufa a $65^{\circ} \mathrm{C}$, por 48 horas, e pesados. $\mathrm{O}$ valor do peso seco das subamostras foi utilizado para determinação do teor de matéria seca da forragem, e proporção de cada componente. Multiplicou-se o teor de matéria seca da sub-amostra pela quantidade de massa verde coletada no quadro de amostragem, para determinação da massa de forragem por parcela, e posterior conversão para $\mathrm{kg} / \mathrm{ha}$.

Os dados obtidos foram submetidos à análise de variância e as médias dos tratamentos foram comparadas pelo teste de Tukey ao nível de $5 \%$ de probabilidade, utilizando-se o procedimento GLM do SAS Versão 6.12.

Para cada espécie foram avaliadas quatro repetições de acordo com o modelo estatístico:

$\mathrm{Y}_{\mathrm{ij}}=\mu+\mathrm{T}_{\mathrm{i}}+\mathrm{e}_{\mathrm{ij}}$

em que:

$Y_{i j}=$ observação referente à repetição j, da espécie i;

$\mu=$ média geral;

$\mathrm{T}_{\mathrm{i}}=$ efeito da espécie $\mathrm{i}$;

$\mathrm{e}_{\mathrm{ij}}=$ erro aleatório associado a cada observação j, da espécie i

As médias obtidas nos cortes das forrageiras em cada período do ano (chuvoso e seca) foram analisadas separadamente para que pudéssemos avaliar o comportamento das espécies em cada período.

\section{RESULTADOS E DISCUSSÃO}

As gramíneas do presente estudo foram cortadas para avaliação quando a interceptação de luz (IL) do dossel atingiu o valor médio de $95,80 \%$ da luz incidente, um pouco acima dos 95\% preconizados, em função de as parcelas apresentarem diferenças na interceptação luminosa ao longo do período de avaliação, em função de atrasos de leitura causados por finais de semana ou feriados. Em média, nos três anos avaliados (2015, 2016 e 2017), foram realizados 10 cortes por ano, sendo sete cortes realizados na estação chuvosa (16 de outubro a 15 de abril) e três na estação seca (16 de abril a 15 de outubro).

O índice de área foliar (IAF) não apresentou diferença significativa entre as forrageiras avaliadas, observando-se valor médio de 4,00 (Tabela 1). O IAF está diretamente relacionado com o nível de interceptação luminosa do dossel, eficiência fotossintética e crescimento das plantas forrageiras.

A altura média do dossel forrageiro, medida quando este atingiu o IAF crítico, variou em

Tabela 1. Índice de área foliar (IAF), massa de forragem (MFS), massa de folhas (MSF), massa de colmos (MSC) e características morfológicas de cultivares do gênero Brachiaria e Brachiaria híbrida.

\begin{tabular}{lccccccc}
\hline \multicolumn{1}{c}{ Gramínea } \\
IAF & Marandu & Xaraés & Piatã & Paiaguás & MG-4 & Convert & $\mathrm{CV}(\%)^{1}$ \\
Altura (cm) & $4,1 \mathrm{a}$ & $3,9 \mathrm{a}$ & $4,1 \mathrm{a}$ & $4,2 \mathrm{a}$ & $3,9 \mathrm{a}$ & $3,9 \mathrm{a}$ & 5,00 \\
MFS (kg/ha/corte) & 24,8 & 31,7 & 25,4 & 34,0 & 28,3 & 22,7 & - \\
MSF (kg/ha/corte) & $2103,0 \mathrm{c}$ & $2648,3 \mathrm{a}$ & $2202,9 \mathrm{bc}$ & $2605,5 \mathrm{ab}$ & $2840,3 \mathrm{a}$ & $1773,7 \mathrm{c}$ & 8,10 \\
MSC (kg/ha/corte) & $1755,1 \mathrm{bc}$ & $2283,0 \mathrm{a}$ & $1776,7 \mathrm{bc}$ & $1820,6 \mathrm{bc}$ & $1976,5 \mathrm{ab}$ & $1560,1 \mathrm{c}$ & 7,90 \\
Folhas (\%) & $193,5 \mathrm{c}$ & $309,9 \mathrm{~b}$ & $313,6 \mathrm{~b}$ & $629,7 \mathrm{a}$ & $608,9 \mathrm{a}$ & $127,4 \mathrm{c}$ & 13,28 \\
Colmos (\%) & 83,5 & 86,2 & 80,6 & 69,9 & 69,6 & 87,9 & 1,91 \\
Material Morto (\%) & 9,1 & 11,7 & 14,3 & 24,1 & 21,4 & 7,2 & 8,70 \\
\hline
\end{tabular}

Médias seguidas pela mesma letra, na linha, não diferem estatisticamente $(\mathrm{P}<0,05)$ pelo teste de Tukey. ${ }^{1} \mathrm{CV}$ = coeficiente de variação. 
função da gramínea avaliada (Tabela1). Estudos realizados com gramíneas comprovaram a alta correlação entre a interceptação luminosa a altura do dossel forrageiro, independente da época do ano e do estádio fisiológico das plantas, indicando que na prática a altura pode ser utilizada como critério para as tomadas de decisão no manejo do pasto (SILVA, 2004). Contudo, esta altura difere entre espécies e cultivares, sendo influenciada por fatores como genótipo da planta, balanço hormonal, estádio de desenvolvimento, fotoperíodo, temperatura, luminosidade e disponibilidade de água e nutrientes (LANGER, 1963).

A altura média do dossel observada para o capim-xaraés $(31,7 \mathrm{~cm})$, quando a interceptação luminosa do dossel atingiu os $95 \%$, foi semelhante aos valores relatados por outros autores. PEDREIRA et al., (2009) sugerem que em regime de lotação rotativa, o manejo do pastejo do capim-xaraés seja feito observando a altura de entrada ou pré-pastejo de $30 \mathrm{~cm}$ (com 95\% de interceptação luminosa) e saída ou pós-pastejo de $15 \mathrm{~cm}$ para evitar acúmulo excessivo de colmos.

No capim-marandu, a altura do dossel $(24,8 \mathrm{~cm})$, aos $95 \%$ de IL foi semelhante ao observado em outros estudos que utilizaram o mesmo critério de corte. GiAcomini et al., (2009), avaliando condições de referência para a utilização dos pastos de capim-marandu, sob lotação animal rotacionada, estabeleceram altura de pré-pastejo de $25 \mathrm{~cm}$, com $95 \%$ de IL, e de pós-pastejo de $15 \mathrm{~cm}$ na estação chuvosa e $10 \mathrm{~cm}$ na estação seca.

Em pastos sob lotação contínua também foram estabelecidas faixas ótimas de altura para manutenção do pasto, para algumas espécies forrageiras do gênero Brachiaria, que podem variar em função da época do ano, categoria animal e metas de desempenho. De acordo com recomedações da Embrapa, os pastos dos capins marandu, piatã e xaraés, sob lotação contínua, devem ser mantidos com 30 $\mathrm{cm}$ de altura, ao longo do período das águas, aceitando-se uma amplitude de variação de $5 \mathrm{~cm}$ da altura-meta, ou seja de 25 a $35 \mathrm{~cm}$ (EMBRAPA, 2014).

GIMENES et al., (2011), avaliaram a produção animal em pastos de capim-marandu sob lotação intermitente, com duas frequências de pastejo, definidas de acordo com as alturas dos pastos, $25 \mathrm{~cm}$ (95\% IL) e $35 \mathrm{~cm}(100 \%$ IL), e duas doses de fertilizante nitrogenado.
Constataram que no verão as metas de altura pré-pastejo estiveram próximas das metas propostas, no entanto, ficaram abaixo da meta, no outono/inverno, para o tratamento $35 \mathrm{~cm}$ $(31,9 \mathrm{~cm})$, e na primavera, para o tratamento $25 \mathrm{~cm}(21,0 \mathrm{~cm})$. Os autores concluíram que a altura de pré-pastejo de $25 \mathrm{~cm}$ para o capimmarandu é a mais adequada, independente da dose de nitrogênio utilizada.

Com relação ao capim-paiaguás, o IAF crítico do dossel foi atingido com altura média do dossel de $34 \mathrm{~cm}$ (Tabela 1), maior altura observada entre os materiais avaliados. EUCLIDES et al. (2016), avaliando as características do dossel dos capins Piatã e Paiaguás sob lotação contínua, em Campo Grande/MS, adotaram a altura de manejo de $30 \mathrm{~cm}$. Contudo ainda não foram divulgados estudos com avaliação da cultivar Paiaguás sob lotação rotacionada, bem como com a altura do dossel quando este atinge o IAF crítico.

A Brachiaria híbrida Convert HD 364 (anteriormente denominada Brachiaria híbrida cV. Mulato II (CIAT 36087), apresentou altura média do dossel de $23 \mathrm{~cm}$, aos $95 \%$ de IL.

Não foram encontrados trabalhos com avaliação da altura do capim-convert (Mulato II) aos 95\% de IL. Contudo, o valor observado no presente estudo foi menor que o encontrado por Silveira et al. (2016) em Piracicaba/SP, em pastos de capim Mulato I (híbrido de Brachiaria ruziziensis $\times$ Brachiaria decumbens), que relataram altura média de $29,4 \mathrm{~cm}$ na condição de IAF crítico. Os autores recomendam que o capim Mulato I seja manejado adotandose altura de pré-pastejo de $30 \mathrm{~cm}$ e altura de pós-pastejo entre 15 e $20 \mathrm{~cm}$. Tal diferença de altura pode ser justificada pelo fato de o capim Convert (Mulatto II) apresentar características diferentes do capim Mulato I, pois se trata de outro híbrido, com inclusão de outra espécie de braquiária no cruzamento (Brachiaria ruziziensis $\times$ Brachiaria decumbens x Brachiaria brizantha).

Assim como a massa de forragem do pasto, a massa de colmos, folhas e material morto muda em função da espécie, das condições edafoclimáticas, e da estratégia de corte ou pastejo adotada. Diversos estudos, avaliando gramíneas tropicais, confirmaram que o IAF crítico é o ponto ideal para interrupção do crescimento do dossel forrageiro através do pastejo, obtendo-se máximo acúmulo de forragem, com máxima produção de folhas, 
e menor produção de colmos e material senescente (CARNEVALLI et al., 2006; GIACOMINI et al., 2009; EuCLidEs et al., 2015; SiLVEIRA et al., 2016). Além desse ponto, observa-se alterações indesejáveis na estrutura do dossel forrageiro, caracterizadas pelo acúmulo excessivo de colmo e material senescente na massa de forragem no pré-pastejo.

A massa de forragem por corte nas braquiárias avaliadas foi diferente $(\mathrm{P}<0,05)$, observando-se maior massa para as cultivares MG-4, Xaraés e Paiaguás, sendo que esta última não diferiu estatisticamente da cultivar Piatã, que apresentou produção intermediária. As cultivares Marandu e Convert HD 364 apresentaram as menores massas de forragem, não diferindo entre si $(\mathrm{P}>0,05)$ (Tabela 1$)$.

Quando se avaliou especificamente a massa de folhas nos diferentes materiais, verificou-se que a cultivar Xaraés apresentou a maior massa de folhas $(P<0,05)$, sem diferir estatisticamente da cultivar MG-4. O capim Convert, apesar de apresentar a maior porcentagem de folhas entre os materiais avaliados $(87,96 \%)$, teve a menor PMSF, o que contribuiu para a menor PMS total. Já as cultivares MG-4 e Paiaguás, apesar da maior massa de forragem $(\mathrm{P}<0,05)$, apresentaram menor porcentagem de folhas e maior de colmos (Tabela 1). Em parte, isto está relacionado com a maior proporção de colmo que contribuiu para com a maior altura e porte mais ereto destes cultivares.

A porcentagem de folhas, observada para o capim Convert foi maior que o valor encontrado por SILVEIRA et al. (2016), avaliando a estrutura do dossel da Brachiaria híbrida sob pastejo, comparando duas estratégias de lotação rotacionada. Estes autores observaram valor médio de $38,8 \%$ de folhas, quando o pasto foi manejado utilizando-se como meta de prépastejo a condição de 95\% de IL pelo dossel. A maior proporção de folhas, observada no presente estudo, podem estar relacionadas ao fato de que no trabalho citado, as amostras de forragem coletadas para avaliações morfológicas, foram cortadas ao nível do solo, enquanto que no presente ensaio a coleta foi realizada adotando-se a altura de $15 \mathrm{~cm}$ acima do solo, o que contribui para a maior proporção de folhas na amostra.

A maior proporção de folhas na massa de forragem é fundamental para uma dieta de maior qualidade para os animais em pastejo, e consequentemente para seu melhor desempenho. De modo geral, a dieta dos animais em pastejo contém alta proporção de lâminas foliares e baixa proporção de colmos e de material morto (HoDGSON, 1990), em função da seletividade dos animais em pastejo e do maior valor nutritivo das folhas. De acordo com Poppr et al. (1987), a maior proporção de lâminas foliares no dossel contribui para a maior degradabilidade do alimento e menor tempo de retenção no rúmen, o que possibilitará maior consumo no longo prazo. GonTIJo NeTO et al. (2006), afirmam que o consumo de forrageiras tropicais tem correlação positiva com a disponibilidade de forragem total e de folhas, a relação folha/colmo e a altura do dossel, afetando o desempenho de animais em pastejo.

TRINDADE et al. (2007) avaliaram o efeito de estratégias de pastejo rotativo sobre a composição morfológica da forragem consumida por bovinos de corte em pastos de capim-marandu, relatam que o manejo mais adequado é aquele com pastejos realizados quando 95\% da luz incidente são interceptados pelo dossel até altura pós-pastejo de $15 \mathrm{~cm}$, uma vez que nestas condições foram observadas as maiores proporções de lâminas foliares e menores de colmos e de material morto nas amostras de forragem consumida pelos animais (extrusa). Observa-se assim a importância do manejo adequado das forrageiras, respeitandose a altura correspondente aos 95\% de IL, que garante a maior proporção de folhas e maior qualidade da forragem consumida.

Dentre os materiais com maior massa de forragem, o capim-xaraés foi o que apresentou maior porcentagem de folhas $(\mathrm{P}<0,05)$ (Tabela 1). A porcentagem de folhas $(86,2 \%)$ foi semelhante à reportada por PEDREIRA et al. (2009). Estes autores relataram massa de forragem de $2230 \mathrm{~kg} /$ ha de MS para o capimxaraés pastejado aos $95 \%$ de IL, no período de primavera/verão. Desta massa de forragem total, coletada acima da altura de resíduo de $15 \mathrm{~cm}, 88,5 \%$ (1940 kg MS/ha) foi composta por folhas, proporção maior que a observada para os pastos onde de adotou como estratégia de desfolhação $100 \%$ de IL ou baseada no calendário, a cada 28 dias.

De acordo com VAlLE et al. (2004), as principais características positivas da cultivar Xaraés são a alta produção de matéria seca, 
principalmente de folhas, a rápida rebrota e o florescimento tardio, o que permite o prolongando o período de pastejo até a estação seca do ano. Nas avaliações da cultivar Xaraés foi constatado que a mesma é cerca de 15\% mais produtiva do que a cultivar Marandu, permitindo $20 \%$ maior produtividade animal por hectare. Contudo, os autores ressaltam que a cultivar Xaraés não apresentou nível de resistência desejável às espécies de cigarrinhas Notozulia entreriana, Deois flavopicta e Mahanarva, em ensaios sob condições controladas. Esta característica limita sua utilização extensiva em áreas com histórico de problemas com cigarrinhas, e deve ser levada em consideração pelos produtores ao escolher a espécie forrageira para formação do pasto.

A massa de forragem total e a massa de folhas e de colmos foram significativamente influenciadas $(\mathrm{P}<0,05)$ pela estação de avaliação (seca e chuvosa), sendo que a menor produção na época seca do ano (26,6\% da MFS anual) ocorreu em decorrência da menor taxa de crescimento das plantas, e consequentemente menor número de cortes (três), em relação aos sete cortes no período chuvoso, que representaram $73,4 \%$ da massa de forragem total (Tabela 2). Este comportamento já era esperado, pois é típico em regiões tropicais, e ocorre em função da sazonalidade das chuvas e das variações na temperatura e fotoperíodo (EuCLiDEs et al., 2016).

Quando se comparou a produção das cultivares dentro de cada estação, observouse comportamento semelhante ao que ocorreu com a massa de forragem anual. As cultivares Xaraés, MG-4 e Paiaguás apresentaram as maiores massas de forragem $(\mathrm{P}<0,05)$ entre os materiais avaliados, na estação chuvosa. Contudo, a cultivar Xaraés se destacou em função da maior massa de folhas, não sendo observada diferença significativa entre as demais cultivares no período chuvoso $(\mathrm{P}>0,05)$ (Tabela 2).

Os capins-paiaguás e MG-4 apresentaram a maior proporção de colmos entre os materiais avaliados, e o capim-convert a menor $(\mathrm{P}<0,05)$, tanto na estação seca quanto na chuvosa.

No período seco do ano os materiais com maior massa seca de folhas foram Paiaguás, Xaraés e MG-4 $(P<0,05)$, que por sua vez não diferiu estatisticamente da cultivar Piatã $(P>0,05)$. Esta característica é interessante no que diz respeito à possibilidade de uso destas cultivares para prolongar a utilização do pasto durante a época seca (outono/inverno), período mais crítico em relação à disponibilidade e qualidade do pasto, permitindo uma maior

Tabela 2. Altura do dossel, massa de forragem total (MFS), massa de folhas (MSF) e de colmos (MSC) de cultivares do gênero Brachiaria e Brachiaria híbrida, nas estações seca e chuvosa do ano.

\begin{tabular}{|c|c|c|c|c|c|c|c|}
\hline \multirow[t]{2}{*}{ Estação } & \multicolumn{7}{|c|}{ Gramínea } \\
\hline & Marandu & Xaraés & Piatã & Paiaguás & MG-4 & Convert & $\mathrm{CV}(\%)$ \\
\hline & \multicolumn{7}{|c|}{ Altura $(\mathrm{cm})$} \\
\hline Chuvosa & $25,9 \mathrm{~A}$ & $35,8 \mathrm{~A}$ & $26,7 \mathrm{~A}$ & $34,36 \mathrm{~A}$ & $29,0 \mathrm{~A}$ & $23,9 \mathrm{~A}$ & - \\
\hline Seca & $22,0 \mathrm{~B}$ & $28,6 \mathrm{~B}$ & $22,4 \mathrm{~B}$ & $33,74 \mathrm{~A}$ & $26,4 \mathrm{~B}$ & $20,2 B$ & - \\
\hline \multirow[t]{2}{*}{ CV $(\%)$} & 6,52 & 5,73 & 3,66 & 3,78 & 2,18 & 3,87 & \\
\hline & \multicolumn{7}{|c|}{ MFS (kg/ha/ano) } \\
\hline Chuvosa & $15752,8 \mathrm{bc}$ & $20301,4 a$ & $16312,1 b c$ & $17544,1 \mathrm{ab}$ & $20081,6 a$ & $13676,4 \mathrm{c}$ & 8,85 \\
\hline \multirow[t]{2}{*}{ Seca } & 5130,0de & $6896,4 \mathrm{bc}$ & $5631,6 \mathrm{~cd}$ & $8411,7 a$ & $8292,9 a b$ & $3940,1 \mathrm{e}$ & 9,87 \\
\hline & \multicolumn{7}{|c|}{$\operatorname{MSF}(\mathrm{kg} / \mathrm{ha} / \mathrm{ano})$} \\
\hline Chuvosa & $13213,8 b$ & $17200,5 a$ & $13180,6 b$ & $12073,2 b$ & $13944,2 b$ & $12100,0 b$ & 8,13 \\
\hline \multirow[t]{2}{*}{ Seca } & $4202,4 \mathrm{~cd}$ & $5935,0 \mathrm{a}$ & $4862,0 \mathrm{bc}$ & $6040,6 a$ & $5603,5 a b$ & $3385,2 d$ & 9,13 \\
\hline & \multicolumn{7}{|c|}{ MSC (kg/ha/ano) } \\
\hline Chuvosa & $1875,3 b c$ & $2674,3 \mathrm{~b}$ & $2545,4 b$ & $4164,6 a$ & $4813,4 \mathrm{a}$ & $1205,6 c$ & 14,13 \\
\hline Seca & $493,0 \mathrm{bc}$ & $788,8 b$ & $454,8 \mathrm{bc}$ & $2113,8 \mathrm{a}$ & $1702,6 \mathrm{a}$ & $179,7 \mathrm{c}$ & 21,75 \\
\hline
\end{tabular}

Médias seguidas pela mesma letra maiúscula na coluna, e minúscula na linha, não diferem estatisticamente $(P<0,05)$ pelo teste de Tukey. $C V=$ coeficiente de variação. 
taxa de lotação animal.

A Brachiaria brizantha cv. BRS Paiaguás, foi avaliada em comparação com a cultivar Piatã por EucLIDES et al., (2016), com relação às características do dossel e desempenho animal em pastejo, sob lotação contínua. Os autores observaram que o capim-paiaguás apresentou maior acúmulo de forragem e melhor desempenho animal, durante o período seco, quando comparado ao capim-piatã. A maior taxa de acúmulo de forragem do capimpaiaguás, durante a estação seca, resultou em maior porcentagem de folhas, e permitiu uma taxa de lotação $50 \%$ maior que no capim-piatã.

A altura da maior parte das cultivares, ao atingir a IL de $95 \%$, variou em função da estação do ano, sendo que esta altura foi menor no período seco $(\mathrm{P}<0,05)$, com exceção da cultivar Paiaguás, cuja altura ao atingir o IAF crítico não variou $(P>0,05)$ entre as estações seca e chuvosa (Tabela 2). Contudo, é importante ressaltar que no período seco estas gramíneas demoram mais tempo para atingir o IAF crítico e a altura ideal de pastejo. Esta diferença na altura média do dossel, quando este atinge o IAF crítico, precisa ser levada em conta ao se estabelecer metas de manejo durante a estação seca e chuvosa, para que a produção, valor nutritivo e persistência do pasto não sejam comprometidas.

\section{CONCLUSÕES}

Para as condições do Arenito Caiuá Paranaense, as cultivares de Brachiaria brizantha Xaraés, Paiaguás e MG-4 são as melhores alternativas em relação a cultivar Marandu, destacando-se pela maior massa de forragem total e de folhas, particularmente na época seca. A altura de entrada preconizado para as cultivares Marandu e Piatã está em torno de 25 $\mathrm{cm}$, para Xaraés e MG-4 $30 \mathrm{~cm}$, Paiaguás $34 \mathrm{~cm}$, e Convert $23 \mathrm{~cm}$.

\section{REFERÊNCIAS}

BORGES, A.R.; MEZZADRI, F.P. Análise da conjuntura agropecuária Safra 2009/2010: Bovinocultura de Corte. Curitiba: SEAB/ DERAL, 2008. Disponível em: <http:// www.seab.pr.gov.br/arquivos/file/deral/ prognosticos/bovino_corte_2009_10.pdf> Acesso em: 20 fev. 2018.

CARNEVALLI, R.A.; SILVA, S.C.; OLIVEIRA, A.A.; UEBELE, M.C.; BUENO, F.O.;
HODGSON, J.; SILVA, G.N.; MORAES, J.P. Herbage production and grazing losses in Panicum maximum cv. Mombaça pastures under four grazing managements. Tropical Grasslands, v. 40, p.1-8, 2006.

COSTA, F.P.; CORREA, E.S.; MELO FILHO, G.A.; CARDOSO, E.E.; PEREIRA, M.A.; MIRANDA, C.H.B. Avaliação dos impactos econômicos de quatro forrageiras lançadas pela Embrapa. Campo Grande: Embrapa Gado de Corte, 2009. 26p (Embrapa Gado de Corte: Documentos, 174). Disponível em: <http:/ / www.cnpgc.embrapa.br/ publicacoes/doc/doc174.pdf> Acesso em: 17 fev. 2018.

EMBRAPA. Soluções tecnológicas: Manejo do pastejo dos capins Marandu, BRS Piatã e Xaraés (cvs de Brachiaria brizantha) sob lotação contínua. Campo Grande, MS: Embrapa Gado de Corte, 2014. Disponível em: https://www.embrapa. br/busca-de-solucoes-tecnologicas / - / produtoservico/3707/manejo-do-pastejodos-capins-marandu-brs-piata-e-xaraescvs-de-brachiaria-brizantha-sob-lotacaocontinua. Acesso em: 08 mar. 2018.

EUCLIDES, V.P.B;LOPES,F.C.;NASCIMENTO JR., D.; DA SILVA, S.C.; DIFANTE, G.S.; BARBOSA, R.A. Steer performance on Panicum maximum (cv. Mombaça) pastures under two grazing intensities. Animal Production Science, 2015. https://doi. org/10.1071/an14721

EUCLIDES, V.P.B.; MACEDO, M.C.M.; VALLE, C.B.; DIFANTE, G.S.; BARBOSA, R.A.; CACERE, E.R. Valor nutritivo da forragem e produção animal em pastagens de Brachiaria brizantha. Pesquisa Agropecuária Brasileira, v.44, p.98-106, 2009. https://doi.org/10.1590/s0100204×2009000100014

EUCLIDES, V.P.B; MONTAGNER, D.B.; BARBOSA, R.A.; VALLE, C.B.; NANTES, N.N. Animal performance and sward characteristics of two cultivars of Brachiaria brizantha (BRS paiaguás and BRS Piatã). Revista Brasileira de Zootecnia, v.45, p.8592, 2016. https://doi.org/10.1590/s180692902016000300001

FIDALSKI, J.; TORMENA, C.A.; CECATO, U.; BARBERO, L.M.; LUGÃO, S.M.B.; COSTA, M.A.T. Qualidade física do solo em pastagem adubada e sob pastejo contínuo. Pesquisa Agropecuária Brasileira, v.43, p.1583-1590, 2008. https://doi. 
org/10.1590/s0100-204x2008001100018

GIACOMINI, A.A.; SILVA, S.C.; SARMENTO, D.O.L.; ZEFERINO, C.V.; SOUZA JR, S.J.; TRINDADE, J.K.; GUARDA, V.A.; NASCIMENTO JR, D. Growth of marandu palisadegrass subjected to strategies of intermittent stocking. Scientia Agricola, v.66, p.733-741, 2009. https:// doi. org/10.1590/s0103-90162009000600003

GIMENES, F.M.A.; DA SILVA, S.C.; FIALHO, C.A.; GOMES, M.B.; BERNDT, A.; GERDES, L.; COLOZZA, M.T. Ganho de peso e produtividade animal em capimmarandu sob pastejo rotativo e adubação nitrogenada. Pesquisa Agropecuária Brasileira, v.46, p.751-759, 2011. https:// doi.org/10.1590/s0100-204x2011000700011

GONTIJO NETO, M.M.; EUCLIDES, V.P.B.; NASCIMENTO Jr., D.; MIRANDA, L.F.; FONSECA, D.M.; OLIVEIRA, M.P. Consumo e tempo de pastejo por novilhos Nelore em pastagem de capim-tanzânia sob diferentes ofertas de forragem. Revista Brasileira de Zootecnia, v.35, p.60-66, $2006 . \quad$ https://doi.org/10.1590/s151635982006000100007

HODGSON, J. Grazing management: science into pratice. New York: J. Wiley: Longman Scientific and Technical, 1990. 203p.

INSTITUTO AGRONÔMICO DO PARANÁ. Cartas climáticas do Paraná: Edição Ano 2000. Londrina: IAPAR, 2000. CD.

JANK, L.; VALLE, C. B.; RESENDE, R.M.S. 2011. Breeding tropical forages. Crop Breeding and Applied Biotechnology, v.11, p.2734, 2011. https://doi.org/10.1590/s198470332011000500005

LANGER, R.H.M. Tillering in herbage grass. Herbage Abstracts, v.33, p.141-148, 1963.

MACEDO, M.C.M. Aspectos edáficos relacionados com a produção de Brachiaria brizantha cultivar Marandu. In: BARBOSA, R.A. Morte de pastos de braquiárias. Campo Grande: Embrapa Gado de Corte, 2006. p.35-65.

MUZILLI, O.; LAURENTI, A. C.; FUENTES L., R.; FAGUNDES, A. C. A.; FIDALSKI, J.; FREGONEZE, J. A.; RIBEIRO, M. F. S.; LUGAO, S. M. B. Conservação do solo em sistemas de produção nas microbacias hidrográficas do arenito Caiua, Paraná: 1. Clima, solo, estrutura agraria e perfil da produção agropecuária. Londrina: IAPAR, 1990. 55p. (IAPAR. Boletim técnico, 33).

PARSONS, A.J.; JOHNSON, I.R.; HARVEY,
A. Use of a model to optimize the interaction between frequency and severity of intermittent defoliation to provide a fundamental comparison of the continuous and intermittent defoliation of grass. Grass Forage Science, v.43, p.49-59, 1988. https://doi.org/10.1111/j.1365-2494.1988. tb02140.x

PEDREIRA, B.C.; PEDREIRA, C.G.S.; SILVA, S.C. Acúmulo de forragem durante a rebrotação de capim-xaraés submetido a três estratégias de desfolhação. Revista Brasileira de Zootecnia, v.38, p.618-625, 2009. https://doi.org/10.1590/s151635982009000400005

POPPI, D.P.; HUGHES, T.P.; L'HUILLIER, P.J. Intake of pasture by grazing ruminants. In: NICOL, A.M. (Ed.). Livestock feeding on pasture. Hamilton: New Zealand Society of Animal Production, 1987. p.55-64.

SILVA, S.C. Fundamentos para o manejo do pastejo de plantas forrageiras dos gêneros Brachiaria e Panicum. In: SIMPÓSIO SOBRE MANEJOESTRATÉGICODAPASTAGEM, 2., 2004, Viçosa. Anais... Viçosa, MG: UFV, 2004. p. 347-385.

SILVEIRA, M.C.T.; NASCIMENTO JR., D.; RODRIGUES, C.S.; PENA, K.S.; SOUZA JR., S.J.; BARBERO, L.M.; LIMÃO, V.A.; EUCLIDES, V.P.B.; SILVA, S.C. Forage sward structure of Mulato grass (Brachiaria hybrid ssp.) subjected to rotational stocking strategies. Australian Journal of Crop Science, v.10, p.864-873, 2016.

TRINDADE, J.K.; SILVA, S.C.; SOUZA JR, S.J.; GIACOMINI, A.A.; ZEFERINO, C.V.; GUARDA, V. A.; CARVALHO. P.C.F. Composição morfológica da forragem consumida por bovinos de corte durante o rebaixamento do capim-marandu submetido a estratégias de pastejo rotativo. Pesquisa Agropecuária Brasileira, v.42, p.883-890, 2007. https://doi.org/10.1590/ s0100-204x2007000600016.

VALLE, C.B.; EUCLIDES, V.P.B.; PEREIRA, J.M.; VALÉRIO, J.R.; PAGLIARINI, M.S.; MACEDO, M.C.M.; LEITE, G.G.; LOURENÇO, A.J.; FERNANDES, C.D.; DIAS FILHO, M.B.; LEMPP, B.; POTT, A.; SOUZA, M.A. O Capim-Xaraés (Brachiaria brizantha CV. Xaraés) na Diversificacão das Pastagens de Braquiária. Campo Grande: Embrapa Gado de Corte, 2004. 36 p. (Documentos, 149). 